\title{
Allometric Equation for Biomass Determination in Juniperus procera Endl. and Podocarpus falcatus Mirb of Wof-Washa Forest: Implication for Climate Change Mitigation
}

\author{
Eyosias Worku, Teshome Soromessa \\ Center for Environmental Science, Addis Ababa University, Addis Ababa, Ethiopia
}

Email address:

Eyoyapi@yahoo.com (E. Worku)

\section{To cite this article:}

Eyosias Worku, Teshome Soromessa. Allometric Equation for Biomass Determination in Juniperus procera Endl. and Podocarpus falcatus Mirb of Wof-Washa Forest: Implication for Climate Change Mitigation. American Journal of Life Sciences. Vol. 3, No. 3, 2015 , pp. $190-202$. doi: $10.11648 /$ j.ajls.20150303.20

\begin{abstract}
Estimation of net above ground biomass in forest ecosystems by non-destructive means requires the development of allometric equations, to allow prediction of above ground biomass from readily measurable variables such as Diameter at Breast Height (DBH). Equations of this type have not been well developed for trees of Wof-Washa Forest. In the present study, trees of two species namely Juniperus procera and Podocarpus falcatus, with three diameter classes $(30-50 \mathrm{~cm}, 51-70 \mathrm{~cm}$ and $71-100 \mathrm{~cm}$ ) with the aim of developing appropriate allometric equations were characterized. Each species considered separately, there was significant variation among the slopes and elevations of the equations obtained for each. The allometric equation that was obtained for the two species had significant $(\mathrm{P}>0.000)$ fit for linear model. The difference between DBH-biomass relationships among these species can be attributed to differences in the distribution of biomass among trunk-plus-largebranches, secondary branches and leaves, and also woody tissue density. Comparison of these results with those obtained using a previously published allometric model revealed significant differences with biomass estimation. It is believed that previously published allometric model corresponding to above ground biomass in dry forests may bear errors, and propose the new equations to be used in the future for the two species and that other one have to become developed for the remaining species.
\end{abstract}

Keywords: Above Ground Biomass, Allometric Equations, Climate Change Mitigation, Wof-Washa Forest, Non-Destructive Method

\section{Introduction}

Estimation of forest biomass is the most accurate and economical way of studying the change in carbon stocks. Studying carbon stocks has the capacity to measure the amount of carbon which accumulated in specific forest. The method which has mostly been used for estimate forest biomass is through the help of allometric equation. Allometry is all about studying the relative size of plant parts. Usually relationship between diameters at breast height (DBH), tree height, total biomass and leaf weight, etc. Due to their sake of energy utilization trees consume $\mathrm{CO}_{2}$ and release $\mathrm{O}_{2}$ through the process called photosynthesis. This process is one of the media that carbon passes through in its life cycle and much of the carbon, almost half of the carbon they consumed, is stack in the tissues of a tree. By studying the relative size of plant parts it is possible to measure the biomass of a tree which also has potentials to estimate how much carbon stock is present in plant parts. Therefore, estimation of biomass is crucial to indicate the carbon sequestration potential of a forest or a tree and also it is very important to assess the impact of climate change and sustainable forest management. Measurement of biomass should take place at local and regional scales for estimating their carbon sequestration and evaluate ecosystem response to carbon change and anthropogenic disturbance. This local and regional scale estimation of biomass will have advance role to cope up the general UNFCCC goal which was stabilizing the greenhouse gases in the atmosphere, forests or trees (UNFCCC, 2006). 
Nevertheless, biomass estimation through allometric equation is very vital for mitigation of climate change and sustainable management of forest, but there is no universally accepted allometric equation for biomass prediction (Wang, 2006). This fact makes biomass estimation very difficult and some trees are found in places where trees can't be touched and these places called protected areas. Moreover, weighing trees in the field is the most accurate method of estimating biomass. Without cutting, at least two or three small branches per tree, it is impossible to deal with biomass measurement and these things make uncertainty in the field (Ketterings et al., 2001).

The other issue related with developing allometric equation is that the presence of generalized allometric equation and species specific allometric equation in a certain forest. Generalized allometric equation is one equation that developed by measuring of the whole forest mostly it encompasses many tree species as one component and the equation can be functional for other forests but the forest should be found in the same ecological zones. The relationship between biomass and tree dimensions differs among species and may also be affected by site characteristics and climate conditions(IPCC, 2007). Species specific allometric equation, however, is an equation developed by only for a particular tree species and it is capable of estimating biomass of the other same species elsewhere. The accuracy or uncertainty of models is an important aspect that is mentioned in the different instrument of Kyoto protocols. To reduce uncertainty accurate carbon accounting methods are required. Therefore, Species specific allometric equation is better than generalized allometric equation and the developments of new species specific allometric equations are necessary to achieve higher level of accuracy (Basuki et al., 2009). This study used Non-destructive method for biomass estimation of Juniperus procera and Podocarpus falcatus to develop allometric equation using the guideline of FAO (FAO, 2012). And the study took place at Wof-Washa Forest, which is located in the Amhara National Regional State, Northwestern high lands of Ethiopia, stretching in three districts called Baso, Ankober and Tarma Ber. The most dominant tree species in this Forest is Juniperus procera and Podocarpus falcatus which are also indigenous species.

In Ethiopia and elsewhere species specific allometric equation for indigenous plants is almost none. As a result, available information regarding the topic is less and lacking. Therefore, this research is expected to provide basic information about the potential capacity of particular indigenous plants under the study to sequester carbon by developing allometric equation using the non-destructive method. Therefore the objective of this study is for the first time to develop and evaluate allometric models for estimating above and belowground biomass of Juniperus procera and Podocarpus falcatus indigenous plant species in Wof-Washa Forest and its implication for the role of climate change mitigation.

\section{Material and Methods}

\subsection{Study Area}

Wof-Washa Forest is located in the central highlands of Ethiopia in Northern Shoa Zone. It spreads over two districts of Ankober and Baso \& Worana. It is characterized by extremely steep slopes on the east side of the mountains. Wof-Washa Forest is located in the Amhara National Regional State, North Showa Zone, Central highlands of Ethiopia. It extends between longitudes $39^{\circ} 40^{\prime}$ and $39^{\circ} 50^{\prime}$ East and latitudes $9^{0} 35^{\prime}$ and $9^{0} 50^{\prime}$ North (Figure. 1). It spreads over three districts of Ankober in the south and south west, Baso \& Worana in the north and northwest and Tarmaber in the northeast. The geology of Wof -Washa Forest was described byBekele (1993). The escarpment is part of the catchments of the Awash River system which drains into the northern Rift Valley. On the other hand, the Wof-Washa Forest is part of the system that supplies water sources for Lake Tana - the official source of the Blue Nile(Teketay and Bekele, 1995). The topography of WofWasha Forest (WWF) is characterized by extremely steep slopes on the east side of the mountains. The sides of the mountains are too steep that the Forest could be one of the most inaccessible forests in the country. Inaccessibility seems to be the only reason for its survival to the present day. While there is no climatic data for the Forest area itself, the data from the nearest station were collected from the National Meteorological Agency. The nearest station to the Forest was Debiresina station. From the data the annual rainfall of Debiresina station in the last 10 years was 1400 $\mathrm{mm}$. The figure below shows the two rain peaks in April (belg rain) and August (Meher rain) respectively. The temperature data was also taken from the nearest weather because, there was no meteorological station in Wof-Washa Forest and it was collected from Gudoberet station. The maximum and minimum mean monthly temperature was $18.91^{\circ} \mathrm{C}$ and $4.57^{\circ} \mathrm{C}$ respectively.

\subsection{Juniperus Procera}

Juniperus procera is a medium-sized tree reaching 20-25 $\mathrm{m}$ (rarely $40 \mathrm{~m}$ ) tall, with a trunk up to $1.5-2 \mathrm{~m}$ diameter and a broadly conical to rounded or irregular crown. The leaves are of two forms, juvenile needle-like leaves $8-15 \mathrm{~mm}$ long on seedlings, and adult scale-leaves $0.5-3 \mathrm{~mm}$ long on older plants, arranged in decussate pairs or whorls of three. It is largely dioecious with separate male and female plants, but some individual plants produce both sexes. The cones are berry-like, 4-8 $\mathrm{mm}$ in diameter, blue-black with a whitish waxy bloom, and contain 2-5 seeds; they are mature in 12-18 months. The male cones are $3-5 \mathrm{~mm}$ long, and shed their pollen in early spring.

\subsection{Podocarpus Falcatus}

Podocarpus falcatusis an evergreen tree up to $46 \mathrm{~m}$ in nature but quite smaller if planted, with a long clean and cylindrical trunk. The crown is slender with a light 
branching system or sub-opposite or verticellate spreading limbs or small, with crowded branches. The bark is thin, rather smooth and grayish-brown to dark brown in color. It later exfoliates into rectangular to irregular flakes up to 3 $\mathrm{cm}$ long. The blaze is pink in color. Leaves vary in disposition sometimes being spirally arranged, but at others in two opposite or sub-opposite ranks. They are shortly petiolate and linear to linear-lanceolate, narrowing abruptly to a sharp or blunt apex and basally to a slightly twisted short stalk. The adult leaf is $3-5 \times 0.3-0.5 \mathrm{~cm}$; the midrib of the adult leaf is not prominent above but is well marked beneath. The leaf color is dark green, often with a grayish bloom.

\subsection{Sampling and Analysis}

A total of 24 Juniperus procera and Podocarpus falcatus individual plants from four plots, (six trees per plot for each species) were selected. According toFAO (2012), guideline there were lot of work had been done by selecting a few trees for the estimation of biomass for example, from eight trees in Brazil and twelve trees in democratic republic of Congo.Wang (2006) andAboal et al. (2005) also selected 100 trees for 10 different species and 80 individuals for five species. In order to minimize the error of sampling plants were classified in to three groups based on DBH rage from $30 \mathrm{~cm}-50 \mathrm{~cm}, 51 \mathrm{~cm}-70 \mathrm{~cm}$ and $71 \mathrm{~cm}-100 \mathrm{~cm}$. Totally 24 individual plants covered the variability of Juniperus procera biomass in the study area. The individual plants were located in the immediate delineated area within the sample plot of 25 $\mathrm{m} \times 25 \mathrm{~m}$ quadrant and all individuals of $\mathrm{DBH}(30 \mathrm{~cm}-50 \mathrm{~cm}$, $51 \mathrm{~cm}-70 \mathrm{~cm}$ and $71 \mathrm{~cm}-100 \mathrm{~cm}$ ) were identified for Juniperus procera and Podocarpus falcatus. From three DBH classes two individual plants were then randomly selected for each plot.

\subsection{Above ground Biomass Estimation}

Forest regulations meant that trees could not be felled, so AGB was estimated by Non-destructive methods. For the purposes of measurement and analysis, the trees were divided into separate architectural elements as trimmed small branch, untrimmed large branch and trunk. Generally, two or three small branches per individual plant were destructed. Trunk weights were estimated from serial measurements of height, diameter and section volume using parabolic estimation of trunk shape. These estimates were used to develop whole-tree regressions of trunk and canopy component weight.

\subsection{Trimmed Fresh Biomass}

Leaves were trimmed from the branches and determine (by weighing separately) the fresh biomass of the leaves from the trimmed branches (Btrimmed fresh leaf) and the fresh biomass of the wood from the trimmed branches (Btrimmed fresh wood).Then through random sampling of the leaves, from the trimmed branches, at least three samples of leaves, from three different branches, were generally required to constitute the aliquot and measured its fresh weight (B aliquot fresh leaf in $\mathrm{g}$ ). An aliquot of the wood was also taken at random from the trimmed branches, without debarking. The fresh volume of the wood aliquot were measured later in the lab, and the value used to determine mean wood density.

\subsection{Untrimmed Fresh Biomass}

Untrimmed biomass was measured indirectly as nondestructive. The different branches in the trimmed tree were first numbered. The small untrimmed branches were processed differently from the large branches and the trunk. For the small branches, only basal diameter was measured. The biomass of these small untrimmed branches was estimated from the relationship between their basal diameter and their mass. The biomass of the trunk and the large branches was estimated from measurements of volumes (Vi in $\mathrm{cm}^{3}$ ) and mean wood density ( $\rho$ in $\mathrm{g} \mathrm{cm}-3$ ). The large branches and trunk should be divided virtually into sections that were then materialized by marking the tree. The volume $\mathrm{Vi}$ of each section i was obtained by measuring its diameter (or its circumference) and its length. Sections about one meter in length were preferably chosen in order to consider diameter variations along the length of the trunk and branches.

The dry biomass of the tree was obtained by the sum of the trimmed dry biomass and the untrimmed dry biomass(FAO, 2012).

$$
\text { Bdry }=\text { Btrimmed dry }+ \text { Buntrimmed dry }
$$

From the fresh biomass, B aliquot fresh wood of a wood aliquot, B aliquot fresh leaves of a leaves aliquot and its dry biomass B aliquot dry wood and dry leaves, the moisture content of the wood were measured by the following equations respectively as given in (including bark)(FAO, 2012).

$$
\mathrm{X} \text { wood }=\frac{\mathrm{B}_{\mathrm{dry} \text { wood }}^{\text {aliquot }}}{\mathrm{B}_{\text {fresh wood }}^{\text {aliqut }}}, \text { and X leaf }=\frac{\mathrm{B}_{\text {dry leaf }}^{\text {aliquot }}}{\mathrm{B}_{\text {fresh leaf }}^{\text {aliqot }}}(\text { equ. } 2 \text { \& } 3)
$$

Trimmed dry biomass can then being calculated:

$$
\begin{array}{r}
\text { Btrimmed dry }=\text { Btrimmed fresh wood } \times \text { xood }+ \\
\text { Btrimmed fresh leaf } \times \text { x leaf } \quad(\text { equ. } 4)
\end{array}
$$

Where Btrimmed fresh leaf was the fresh biomass of the leaves stripped from the trimmed branches and Btrimmed fresh wood was the fresh biomass of the wood in the trimmed branches.

After determining the trimmed components of the tree then it is possible to calculate the untrimmed components of the tree. Two calculations were required to calculate the dry biomass of the untrimmed part (i.e. that still standing): one for the small branches, the other for the large branches and the trunk. The untrimmed biomass was the sum of the two results(FAO, 2012).

$$
\begin{array}{r}
\text { Buntrimmed dry }=\text { Buntrimmed dry branch }+ \\
\text { Bdry section }
\end{array}
$$


According to FAO (2012), each section i of the trunk and the large branches may be considered to be a cylinder of volume (Newton's formula or truncated cone volume formula).

$$
\mathrm{Vi}=\frac{\pi}{8} 8 \mathrm{Li}\left(\mathrm{D}_{1 \mathrm{i}}^{2}+\mathrm{D}_{2 \mathrm{i}}^{2}\right)
$$

Where Vi was the volume of the section i, Li its length, and D1 $i$ and D2 $i$ were the diameters of the two extremities of section i.

The dry biomass of the large branches and trunk was the product of mean wood density and total volume of the large branches and trunk(FAO, 2012).

$$
\text { B dry section }=\bar{\rho} \times \sum_{i} V i
$$

Whereas mean wood density was calculated by

$$
\rho=\frac{B_{\text {drywood }}^{\text {aliquot }}}{V_{\text {fresh wood }}^{\text {aliquot }}}
$$

The dry biomass of the untrimmed small branches was calculated using a model between dry biomass and basal diameter. This model was established by following the same procedure as for the development of an allometric model(FAO, 2012).

Power type equations were used:

$$
\text { Bdry branch }=a+b D^{c}
$$

Where $\mathrm{a}, \mathrm{b}$ and $\mathrm{c}$ were model parameters and D branch basal diameter. Using a model of this type, the dry biomass of the untrimmed branches was:

$$
\text { Buntrimmed dry branch }=\sum_{J}\left(a+b D_{J}^{C}\right)(\text { equ.10) }
$$

Where the sum was all the untrimmed small branches and $D_{J}$ was the basal diameter of the branch.

\subsection{Estimation of Below Ground Biomass (BGB)}

Below ground biomass estimation was much more difficult and time consuming than estimating aboveground biomass (Geider et al., 2001). According to MacDicken (1997), standard method for estimation of below ground biomass can be obtained as $20 \%$ of above ground tree biomass i.e., rootto-shoot ratio value of 1:5 was used. Similarly, Pearson et al. (2013) described this method as it is more efficient and effective to apply a regression model to determine belowground biomass from knowledge of biomass aboveground. Thus, the equation developed by MacDicken (1997), to estimate below-ground biomass was used. The equation is given below:

$$
\mathrm{BGB}=\mathrm{AGB} \times 0.2
$$

Where, BGB was below ground biomass, AGB was above ground biomass, 0.2 is conversion factor (or $20 \%$ of AGB).

\subsection{Data Analysis}

After the data collection was completed, data analysis of
Juniperus procera and Podocarpus falcatus measured in the forests were accomplished by organizing and recording on the excel data sheet. The data obtained from section volume, fresh biomass of small trimmed branches, large branch and trunk biomass, fresh weight of trimmed leaf and dry weight of trimmed leaf, fresh trimmed wood, and fresh trimmed dry wood were analyzed using Statistical Package R software (version $\mathrm{R} \mathrm{3.0.0.)}$ and it also used to develop allometric equation.

\section{Results and Discussion}

\subsection{Biomass Estimation}

The overall process that used to determine biomass of Juniperus procera and Podocarpus falcatus followed a series of procedures as FAO (2012),indicated and the first step was to classify the trees into three $\mathrm{DBH}$ classes which help to accommodate the variability of most of the tree sizes in the selected area. Hence 24 trees per species were selected at 4 plots based on the DBH classes.

\subsection{Trimmed Fresh Biomass}

As indicated in Table 1 the fresh trimmed wood of Juniperus procera had a mean result of 564.47 gm from the total of 24 branches which had the sum value of 13,547.21 gm and the range was $607.21 \mathrm{gm}$. After oven drying the mean value became $273.10 \mathrm{gm}$ with a difference of 299.5 gm. The total amount of oven dry trimmed wood branch was $6,554.38 \mathrm{gm}$. The total fresh leaf weight was $12,055.59$ gm and with mean value of $502.32 \mathrm{gm}$. After oven drying, it became $226.81 \mathrm{gm}$. The sum of all 24 individual trimmed tree leaf branches had a value of $544.4 \mathrm{gm}$. Then this result gave the Xwood and Xleaf measurements according to equation (4).

The total Xwood value measured was $11.6 \mathrm{gm}$ and total Xleaf of $10.81 \mathrm{gm}$ and the mean value of $0.48 \mathrm{gm}$ and $0.45 \mathrm{gm}$ respectively. The overall objective of equation (4) was to determine the biomass of trimmed branch and the mean value of trimmed biomass which was $0.50 \mathrm{gm}$ from 24 individuals and sum of its value was $12.00 \mathrm{~kg}$. The fresh trimmed branch (wood) of Podocarpus falcatus had a total value of $14,814.00 \mathrm{gm}$ and a mean value of $617.25 \mathrm{gm}$ from 24 individuals with a range of $946.79 \mathrm{gm}$. After oven drying, a total value of $7,159.15 \mathrm{gm}$ and mean of $298.29 \mathrm{gm}$. The fresh leaf had also a total of 12,117.14gm with a mean value of $504.88 \mathrm{gm}$. It had a maximum value of $796 \mathrm{gm}$ and a minimum value of $353.47 \mathrm{gm}$. After oven drying, the total value of leaf of Podocarpus falcatus became 5,288.53gm and with a mean value of $220.35 \mathrm{~g}$. Based on equation (4) the mean Xwood and Xleaf of Podocarpus could be estimated and had a value of $0.47 \mathrm{gm}$ and $0.43 \mathrm{gm}$ respectively. B trimmed or biomass of trimmed branch of Podocarpus falcatus was then estimated and had a total value of $12.45 \mathrm{~kg}$ with a mean value of $0.52 \mathrm{gm}$. 
Table 1. Trimmed components for Juniperus procera and Podocarpus falcatus.

\begin{tabular}{llllllll}
\hline Tree component & N & Range & Minimum & Maximum & Sum & Mean & Std. Deviation \\
\hline Before oven(wood)Juniperus & 24 & 607.21 & 374.61 & 981.82 & 13547.21 & 564.47 & 137.99 \\
After oven (wood) Juniperus & 24 & 299.50 & 159.38 & 458.88 & 6554.38 & 273.10 & 72.59 \\
Before oven(leaf) Juniperus & 24 & 291.47 & 346.37 & 637.84 & 12055.59 & 502.32 & 78.43 \\
After oven(leaf) Juniperus & 24 & 189.82 & 104.45 & 294.27 & 5443.50 & 226.81 & 40.12 \\
XwoodJuniperus & 24 & 0.27 & 0.38 & 0.65 & 11.60 & 0.48 & 0.05 \\
XleafJuniperus & 24 & 0.21 & 0.3 & 0.51 & 10.81 & 0.45 & 0.05 \\
Before oven(wood)Podocarpus & 24 & 946.79 & 396.63 & 1343.42 & 14813.99 & 617.25 & 212.69 \\
After oven(wood) Podocarpus & 24 & 499.39 & 129.06 & 628.45 & 7159.15 & 298.30 & 115.29 \\
Before oven(leaf) Podocarpus & 24 & 442.53 & 353.47 & 796.00 & 12117.14 & 504.88 & 88.69 \\
After oven(leaf) Podocarpus & 24 & 177.05 & 152.8 & 329.85 & 5288.53 & 220.36 & 43.83 \\
Xwood Podocarpus & 24 & 0.24 & 0.33 & 0.57 & 11.44 & 0.48 & 0.06 \\
XleafPodocarpus & 24 & 0.15 & 0.36 & 0.51 & 10.49 & 0.44 & 0.04 \\
B trimmed Juniperus & 24 & 0.40 & 0.36 & 0.75 & 12.00 & 0.50 & 0.08 \\
B trimmed Podocarpus & 24 & 0.55 & 0.33 & 0.88 & 12.44 & 0.52 & 0.14 \\
\hline
\end{tabular}

Note:

Before oven (wood) Juniperus: fresh weight of trimmed branch wood; Before oven (wood) Podocarpus: fresh weight of trimmed branch wood After oven (wood) Juniperus: dried weight of trimmed branch wood; After oven (wood) Podocarpus: dried weight of trimmed branch wood Before oven (leaf) Juniperus: fresh weight of trimmed branch leaf; Before oven (leaf) Podocarpus: fresh weight of trimmed branch leaf After oven (leaf) Juniperus: fresh weight of trimmed branch leaf; After oven (leaf) Podocarpus: fresh weight of trimmed branch leaf

Xwood Juniperus: moisture content of wood aliquot; Xwood Podocarpus: moisture content of wood aliquot

Xleaf Juniperus: moisture content of leaf aliquot Xleaf Podocarpus moisture content of leaf aliquot

B trimmed Juniperus: Dry biomass of a single trimmed branch; B trimmed Podocarpus: Dry biomass of a single trimmed branch

\subsection{Untrimmed Fresh Biomass}

The biomass of each individual tree was estimated through (semi) non- destructive method that was explained in the guideline of FAO (2012) by indirect weighting of trees. Weighting of trees was carried out by measuring diameters from the ground level to the tip of the trees along one meter length and with the inclusion of large branches. The fresh biomass of trunk and large branches were calculated from volume and density measurements and it was hypothesized that each section cut was considered to be cylinders. The section cut part had a length of one meter and diameter of the initial and after one meter final length. According to equation (6), the volume of each cut section was determined and the total volume of each tree was also known. Density was measured out by displacement theory.

Table 2. Trimmed branch density $\left(\mathrm{g} / \mathrm{cm}^{3}\right)$ and whole tree volume $\left(\mathrm{m}^{3}\right)$.

\begin{tabular}{lllll}
\hline \multirow{2}{*}{ Tree } & Density of a tree $\left(\mathbf{g} / \mathbf{c m}^{\mathbf{3}}\right)$ & & Volume of a tree $\left(\mathbf{m}^{\mathbf{3}}\right)$ & Podocarpus \\
\cline { 2 - 5 } & Juniperus & Podocarpus & Juniperus & 1.91 \\
\hline 1 & 498.78 & 537.46 & 3.06 & 1.88 \\
2 & 528.18 & 553.84 & 1.74 & 3.00 \\
3 & 432.72 & 504.41 & 2.78 & 1.13 \\
4 & 530.86 & 453.33 & 3.02 & 0.83 \\
5 & 516.47 & 474.30 & 1.23 & 1.28 \\
7 & 620.88 & 531.96 & 3.89 & 1.89 \\
8 & 393.53 & 593.57 & 2.62 & 0.67 \\
9 & 521.32 & 432.21 & 2.00 & 1.30 \\
10 & 452.31 & 446.85 & 3.72 & 2.02 \\
11 & 529.75 & 370.78 & 1.37 & 1.15 \\
12 & 456.32 & 461.74 & 3.05 & 1.32 \\
13 & 523.84 & 473.80 & 1.47 & 1.24 \\
14 & 573.67 & 564.09 & 1.79 & 1.14 \\
15 & 473.15 & 561.62 & 0.93 & 2.50 \\
16 & 510.23 & 457.59 & 0.40 & 1.19 \\
17 & 500.37 & 460.78 & 5.56 & 6.48 \\
18 & 537.65 & 440.71 & 0.78 & 3.03 \\
19 & 464.09 & 465.00 & 1.06 & 4.18 \\
20 & 453.41 & 579.28 & 7.85 & 4.10 \\
21 & 479.29 & 560.83 & 4.73 & 6.36 \\
22 & 556.73 & 330.92 & 3.78 & 3.66 \\
23 & 578.09 & 349.79 & 0.97 & 2.62 \\
\hline
\end{tabular}


The fresh volume of trimmed branch (wood) was then estimated and had a value as mentioned in the table above for 24 individuals of Juniperus procera and Podocarpus falcatus from their trimmed branch. Volume of trimmed small branch had a critical role for determination of density which was vital for estimation of the total biomass of a tree.

Semi destructive way of biomass estimation hypothetically assumes that density considered being the same in all compartments of a tree and the entire biomass of a tree then took the small branch's density as a density of the whole tree. Determination of density and volume (trunk) of a tree then had a capacity to estimate dry section or the sections that was existed at the trunk and classified by 1 meter each.

Table 3. Untrimmed components of Juniperus procera and Podocarpus falcatus.

\begin{tabular}{llllll}
\hline Section/s & N & Range & Minimum & Maximum & Mean \\
\hline Dry section Juniperus & 24 & 3353.49 & 204.11 & 3557.61 & 31772.00 \\
Dry branch Juniperus & 24 & 11.78 & 4.81 & 16.5841 & 221.654 \\
Dry section Podocarpus & 24 & 2566.54 & 289.68 & 2856.22 & 27976.80 \\
Dry branch Podocarpus & 24 & 8.00 & 2.44 & 10.4325 & 141.67 \\
B untrimmed Juniperus & 24 & 3358.13 & 210.96 & 3569.083637 & 31993.62 \\
B untrimmed Podocarpus & 24 & 2569.59 & 292.12 & 2861.70544 & 13.90 \\
\hline
\end{tabular}

Based on equation (7) the mean value for Juniperus procera dry section became $1,323.88 \mathrm{~kg}$ and maximum and minimum of $3,557.60 \mathrm{~kg}$ and $204.11 \mathrm{~kg}$ respectively. The sum of all 24 samples was also $31,771.97 \mathrm{~kg}$. Similarly the dry section mean value of Podocarpus falcatus was estimated t0 be $1165.7 \mathrm{~kg}$. From the total value of $2,796.79 \mathrm{~kg}$ the maximum and minimum values were $2,856.25 \mathrm{~kg}$ and $289.68 \mathrm{~kg}$ respectively as indicated in Table 3. The next step after determining dry section was determination of dry branch. According to equation (10), estimation of untrimmed small branches uses allometric model. This allometric model was developed for untrimmed small branches using all trimmed branches from 24 individual trees. In order to work through, there were two variables, one dependent and the other independent. In this case the independent variable was represented by $\mathrm{D}$ where it represented basal diameter and the dependent variable was represented by Dry branch where it represents biomass. Therefore, the dry branch in this case was the biomass of trimmed small branch and its basal diameter was the "D". Through the trimmed small branches then the model was formulated.

Dry branch $=0.096+0.0295 \mathrm{D}$ and Dry branch $=0.025+0.036 \mathrm{D}$ for Juniperus procera and Podocarpus falcatus respectively.

ANOVA was carried out to test the model and it was significant at $(\mathrm{P}>0.000)$ for both Juniperus procera and Podocarpus falcatus species. The value of $\mathrm{r}^{2}=0.706$ and
0.771 for Juniperus procera and Podocarpus falcatus respectively. Therefore, to estimate the biomass of untrimmed small branches or dry branches through the model, substitute " $D$ " by measured basal diameters of untrimmed small branches in order to estimate their biomass or dry branch based on equation (10). Using the model, the small untrimmed branches or dry branches of Juniperus had a total value of $221.65 \mathrm{~kg}$ with a maximum and minimum estimation of $16.58 \mathrm{~kg}$ and $4.80 \mathrm{~kg}$ respectively. And it had a mean value of $9.23 \mathrm{~kg}$.

The mean value for Podocarpus falcatus was $5.90 \mathrm{~kg}$ and total value of $141.6 \mathrm{~kg}$ with a minimum and maximum value of $2.44 \mathrm{~kg}$ and $10.43 \mathrm{~kg}$ respectively. This result then was used to calculate the total untrimmed biomass of the tree by adding the dry section and dry branch according to equation (5). Therefore, the mean value of total biomass of untrimmed components of the tree was $1,333.17 \mathrm{kgfor}$ Juniperus procera and 1,171.60kgfor Podocarpus falcatus. Those values were important to estimate untrimmed trunk and large branches or B untrimmed biomass of Juniperus procera and Podocarpus falcatus and they had a mean value of $1,333.1 \mathrm{~kg}$ and $1,171.6 \mathrm{~kg}$ with maximum and minimum value of $3,569.08 \mathrm{~kg}, 210.96 \mathrm{~kg}$ and $2,861.71$, $292.12 \mathrm{~kg}$ respectively. Generally, the biomass of 24 selected individuals for each species are in Fig ( $1 \& 2)$, that different amount of biomass were estimated and this indicates that $\mathrm{DBH}$ is a factor or when $\mathrm{DBH}$ size increases the biomass also increases for both species. 


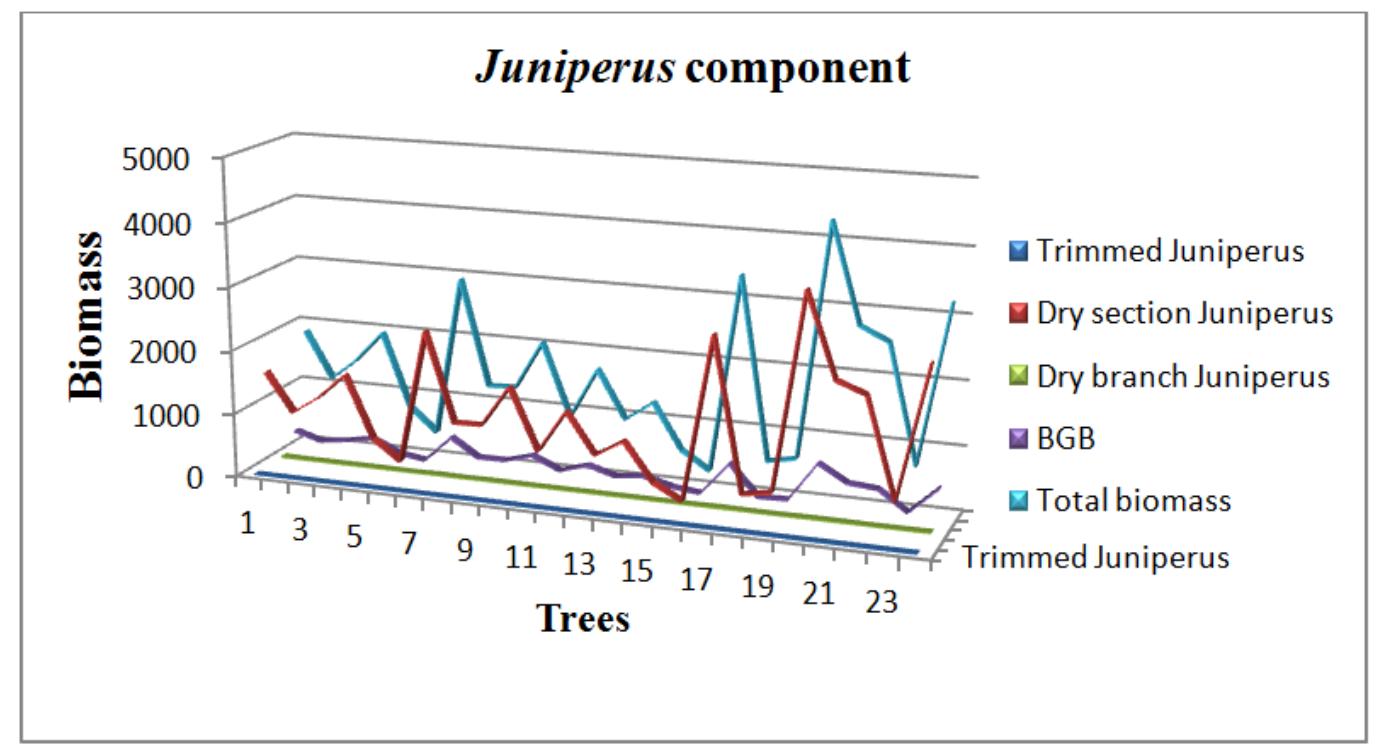

Figure 1. Biomass of Juniperus procera components.

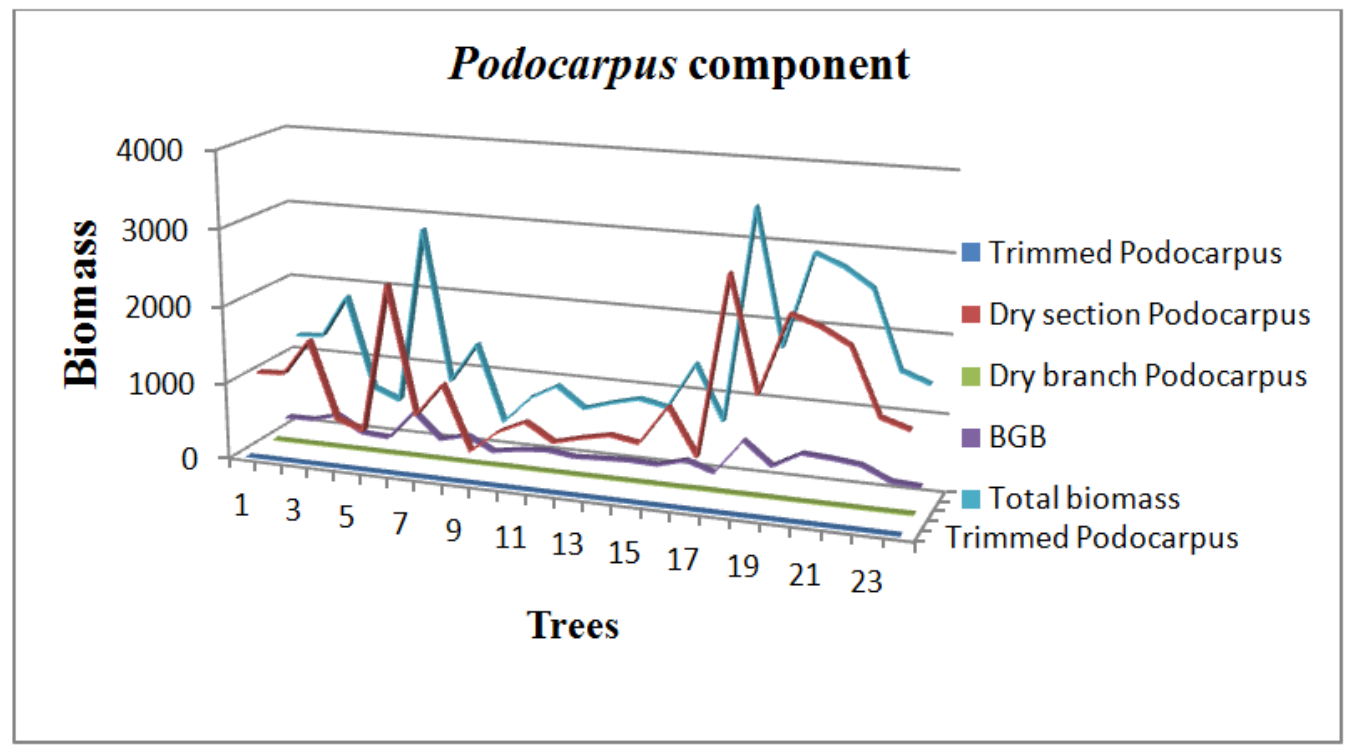

Figure 2. Biomass of Podocarpus falcatus components.

Right at this point, all the compartments were fulfilled to measure the above ground biomass of a tree. All the above mentioned results were used to determine the overall objective of this method (semi destructive) which was measuring of biomass of a tree.

Table 4. AGB, BGB, and Total biomass of Juniperus procera and Podocarpus falcatus.

\begin{tabular}{|c|c|c|c|c|c|c|}
\hline & $\mathbf{N}$ & Range & Minimum & Maximum & Sum & Mean \\
\hline AGB Juniperus & 24 & $3,358.07$ & 211.38 & $3,569.45$ & $3,2005.64$ & $1,333.57$ \\
\hline AGB Podocarpus & 24 & $2,569.57$ & 292.65 & $2,862.22$ & $2,8130.9$ & $1,172.12$ \\
\hline BGB Juniperus & 24 & 671.61 & 42.28 & 713.89 & $6,401.12$ & 266.714 \\
\hline BGB Podocarpus & 24 & 513.91 & 58.53 & 572.44 & 5626.18 & 234.42 \\
\hline Total biomass of Juniperus & 24 & $4,029.69$ & 253.66 & $4,283.34$ & $3,8406.74$ & $1,600.28$ \\
\hline Total biomass of Podocarpus & 24 & $3,083.49$ & 351.18 & $3,434.67$ & $33,757.09$ & $1,406.55$ \\
\hline
\end{tabular}




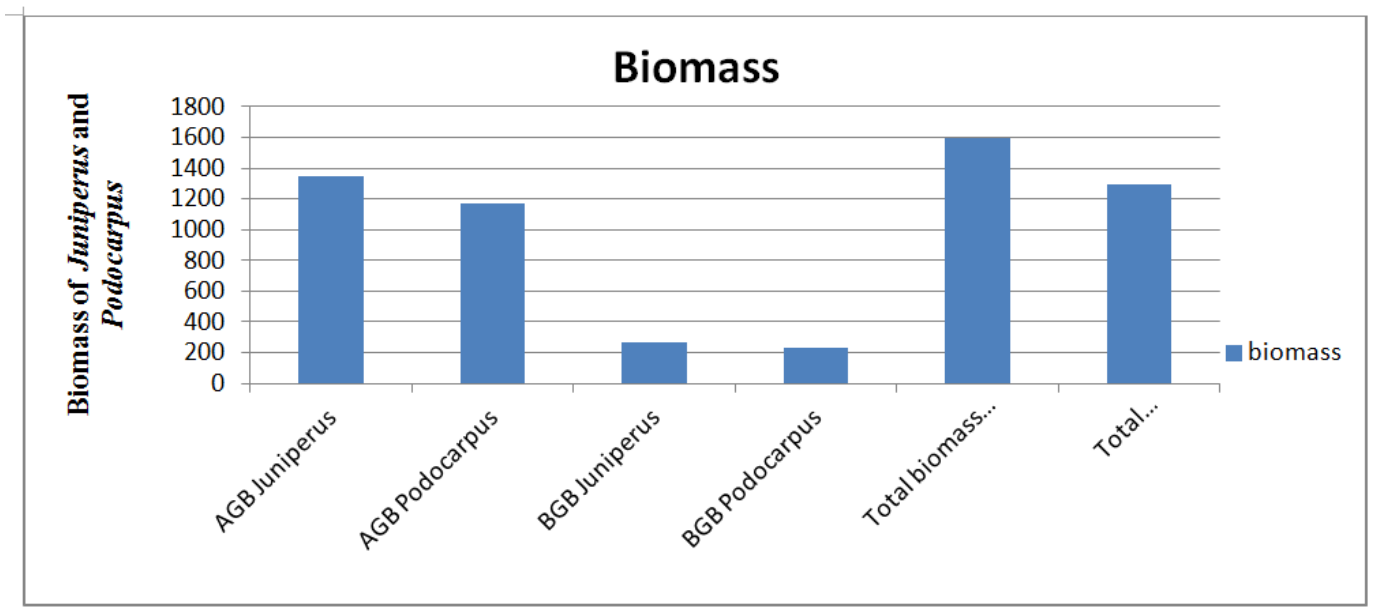

Figure 3. Biomass of $A G B, B G B$, and Total biomass for Juniperus procera and Podocarpus falcatus.

As Table 4 shows, the above ground biomass (AGB) of Juniperus procera had a mean value of $1,333.57 \mathrm{~kg}$ with a range of $3,358.07 \mathrm{~kg}$ and Podocarpus falcatus had a mean value of $1,172.17 \mathrm{~kg}$ with a range of $2,569.57 \mathrm{~kg}$ of above ground biomass (AGB). Determination of below ground biomass (BGB) was held through non-destructive way and following Pearson et al. (2013)who described the method as (BGB $=0.2 * \mathrm{AGB}$ ), a good way of estimation of root. Juniperus procera and Podocarpus falcatus have mean value of BGB of $266.69 \mathrm{~kg}$ and $230.26 \mathrm{~kg}$ respectively. The maximum value for Juniperus procera was $713.89 \mathrm{~kg}$ and a minimum value of $42.28 \mathrm{~kg}$ while Podocarpus falcatus measured a maximum of $572.44 \mathrm{~kg}$ and a minimum of $58.53 \mathrm{~kg}$. The total biomass including BGB was estimated and had a mean value for Juniperus procera and Podocarpus falcatus were $1600.28 \mathrm{~kg}$ and $1296.51 \mathrm{~kg}$ respectively. The maximum and minimum values for Juniperus procera and Podocarpus falcatus also determined and they had values of $4,283.34 \mathrm{~kg}, 253.66 \mathrm{~kg}$ and $3,434.67 \mathrm{~kg}, 253.43 \mathrm{~kg}$ respectively. The biomass of Juniperus procera and Podocarpus falcatus species showed differences one from another as Figure 3 shows.

\subsection{Allometric Equations}

Significant $(\mathrm{p}<0.000)$ allometric equations were developed for all tree compartments with $\mathrm{y}$ - intercept and slope value of the two species. As shown in Table 5, the relationship between biomass and DBH has great linearity. The two models are the best performing model for all compartments of both species. The linear model which uses basal diameter of Juniperus procera as independent variable and trimmed Juniperus procera as dependent variable shows the $\mathrm{r}^{2}$ value of 0.69 which is significant. However, it is also similar for logarithm model. For Podocarpus falcatus it is also significant with the $\mathrm{r}^{2}$ value of 0.76 but 0.78 for logarithm model. This allometric model was used to estimate the value of all untrimmed small branches for both species. Dry section and above ground biomass (AGB) of Juniperus procera had significant $\left(\mathrm{r}^{2}=0.83\right)$ relationship for both compartments.

The coefficient of intercept is -1556.13 and the slope is 47.73for dry section compartment and for AGB the intercept is -1551.59 and the slope is 47.81 . The total biomass of Juniperus procera also had highly significant value $\left(\mathrm{r}^{2}=0.83\right)$. The linear relationship has an intercept value of -1861.91 and 57.38 slope values. Dry section and above ground biomass (AGB) for Podocarpus falcatus has highly significant $\left(\mathrm{R}^{2}=\right.$ $0.79)$ relationship for both compartments. The coefficient of intercept value is -949.52 and -942.96 respectively. The slope for both compartments is 35.89 . The total biomass of Podocarpus falcatus had high significance $\left(\mathrm{R}^{2}=0.79\right)$ with intercept value of -1131.55 and slope of 43.069 .

Table 5. Best performing models for estimation of Juniperus procera and Podocarpus falcatus trimmed, dry section, AGB and Total biomass (biomass, kg) and (diameter, $\mathrm{cm}$ ).

\begin{tabular}{|c|c|c|c|c|c|}
\hline \multirow{3}{*}{ Compartment } & \multicolumn{5}{|l|}{ Juniperusprocera } \\
\hline & \multirow{2}{*}{ Equation } & \multicolumn{2}{|l|}{ coefficients } & \multicolumn{2}{|c|}{ performance statistics } \\
\hline & & Intercept (a) & slope (b) & r2 & $\mathbf{P}$ \\
\hline \multirow{2}{*}{ Trimmed } & trimmed $=\mathrm{a}+\mathrm{b}$ (basal diameter) & 0.095 & 0.029 & 0.69 & 0.000 \\
\hline & $\ln ($ trimmed $)=\ln (a)+b \ln ($ basal diameter $)$ & -2.472 & 0.657 & 0.69 & 0.000 \\
\hline Drysection & $\operatorname{Ln}($ drysection $)=\ln (\mathrm{a})+\mathrm{b} \ln (\mathrm{DBH})$ & -2.58 & 2.34 & 0.86 & 0.000 \\
\hline Above Ground Biomass(AGB) & $\operatorname{Ln}(\mathrm{ABG})=\ln (\mathrm{a})+\mathrm{b} \ln (\mathrm{DBH})$ & -2.48 & 2.32 & 0.86 & 0.000 \\
\hline Total biomass & $\operatorname{Ln}($ Total biomass $)=\ln (\mathrm{a})+\mathrm{b} \ln (\mathrm{DBH})$ & -2.3072 & 2.32 & 0.86 & 0.000 \\
\hline Compartment & Podocarpusfalcatus & & & & \\
\hline \multirow{2}{*}{ Trimmed } & Trimmed $=\mathrm{a}+\mathrm{b}$ (basal diameter) & 0.025 & 0.035 & 0.76 & 0.000 \\
\hline & $\ln ($ trimmed $)=\ln (a)+b \ln ($ basal diameter $)$ & -2.972 & 0.863 & 0.78 & 0.000 \\
\hline Drysection & $\ln ($ drysection $)=\ln (\mathrm{a})+\mathrm{b} \ln (\mathrm{DBH})$ & 0.361 & 1.79 & 0.84 & 0.000 \\
\hline Above Ground Biomass(AGB) & $\ln (\mathrm{AGB})=\ln (\mathrm{a})+\mathrm{b} \ln (\mathrm{DBH})$ & -0.307 & 1.7855 & 0.84 & 0.000 \\
\hline Total biomass & $\ln ($ Total biomass $)=\ln (\mathrm{a})+\mathrm{b} \ln (\mathrm{DBH})$ & -0.1254 & 1.785 & 0.84 & 0.000 \\
\hline
\end{tabular}




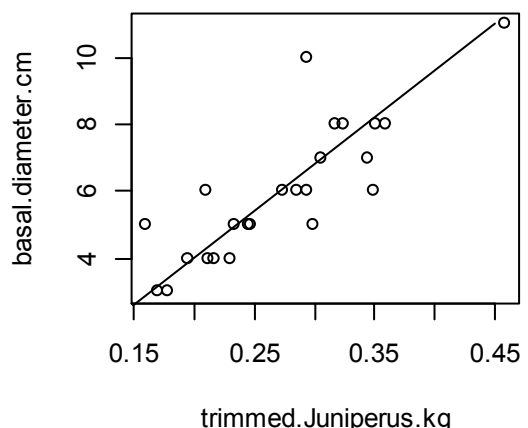

trimmed.Juniperus. $\mathrm{kg}$

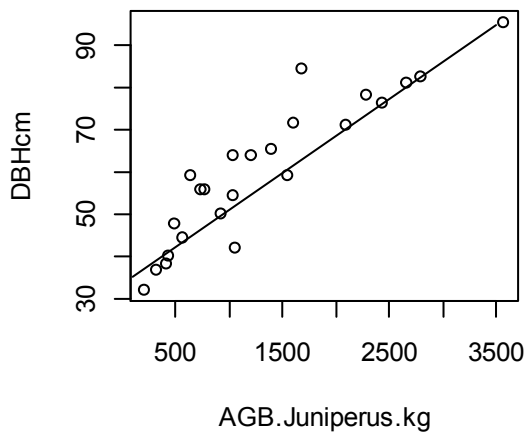

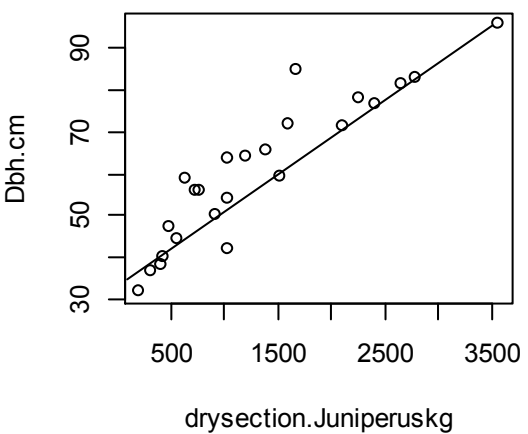

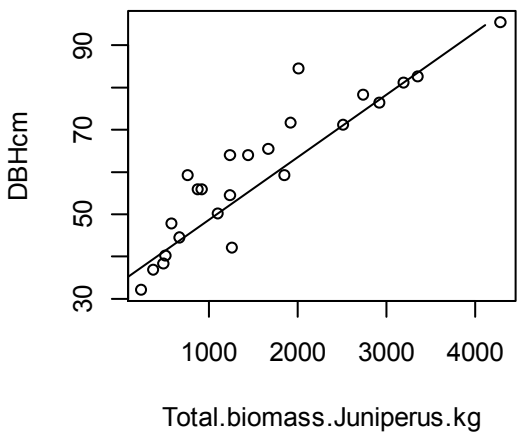

Total.biomass.Juniperus.kg

Figure 4. Relationship between diameters (basal) with biomass of Juniperus procera components.

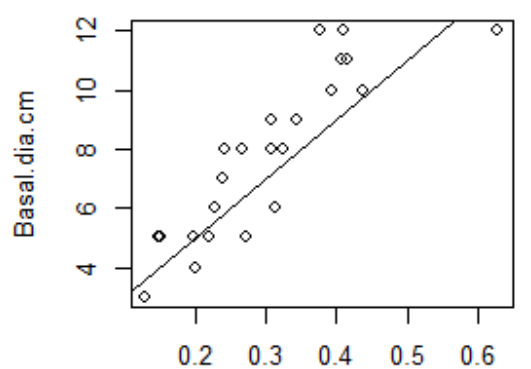

trimmed.podocarpus. $\mathrm{kg}$

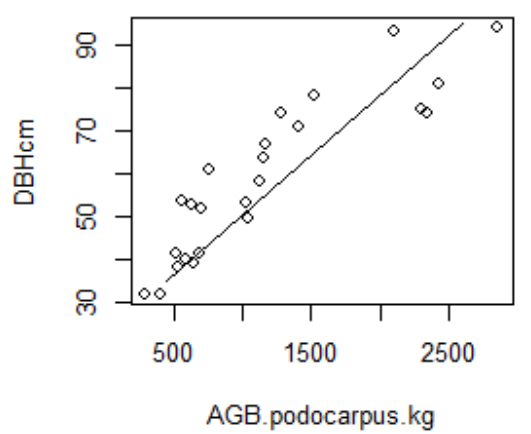

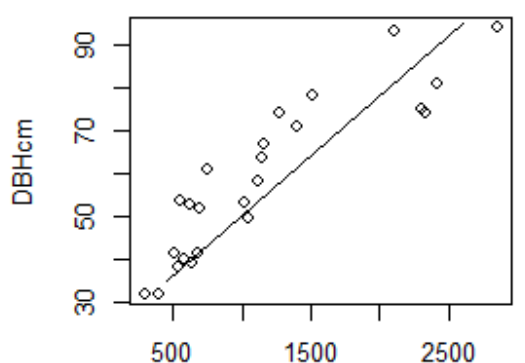

dry.section. podocarpus. $\mathrm{kg}$

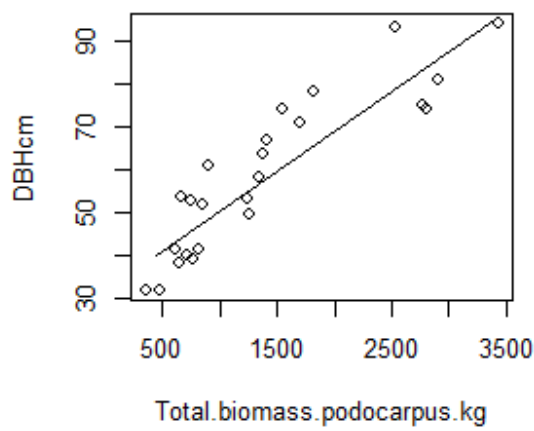

Figure 5. Relationship between diameters (basal) with biomass of Podocarpus falcatus components.

\section{Discussion}

In order to know how much amount of carbon is stored or sequestered in a particular forest or species it is so important that estimation of biomass is made. Biomass is then estimated through allometric equations. Allometric equations generally relate on easily measured independent variable like $\mathrm{DBH}$ to other components like biomass and provide relative accurate estimation (Ketterings et al., 
2001). Despite development of allometric equation, there are very wide and different forms of allometric equation in biomass estimation science. The most common form of allometric equation that is found in the science of biomass estimation is linear model(Ketterings et al., 2001).This study also developed allometric equation based onFAO (2012), guideline for Juniperus procera and Podocarpus falcatus species using the data collected from Wof-Washa Forest and the model best fit at $(\mathrm{P}>0.000)$ in linear regression. Regression models should not be used beyond their range of validity. The models proposed here are valid in the range $30-100 \mathrm{~cm}$ for $\mathrm{D}$.

The biomass estimation of a tree based on species specific allometric equation is more preferable than the general one (Singh et al., 2011). Therefore, this study developed allometric equation through species specific equations. In order to deal with the allometric equation, it is mandatory to estimate the biomass of that particular tree. There are two kinds of biomass estimation mechanisms namely destructive and non-destructive. Both methods have their own merit and demerit (Aboal et al., 2005). From two of these methods, based on environmental protection, it is better to use non-destructive mechanism and it also allow to measure threatened species (Ketterings et al., 2001).

Many allometric equations have been developed through the mechanism that allows trees to be destructively harvested. Most of them followed the same procedure to estimate biomass of a tree. For example (Wang, 2006), develop allometric equation for 10 species in Chinese temperate forests destructively. For all of 10 species, 10 trees were harvested for estimation of biomass. Weighing trees in the field (harvesting) is undoubted and the most accurate method of estimation of biomass and limit the use of conversion coefficients that decrease the accuracy. However, it is time consuming, limited by technical, financial and in some cases legal considerations make it hard to deal with it. Considering these demerits of destructive measurements of biomass this study used nondestructive methods as the mechanism to estimate biomass. The advantage of using such methods is that it consume less time, and could have the capacity to deal with threatened species and enables to study the evolution of individual trees without distorting the environment.

This study also tried to deal with biomass through nondestructive ways but with small modifications, keeping the tree alive. To estimate biomass of a tree through nondestructive means, the main doubt is to fall to estimate density for each species. Density is differing among species and within species but not location(Kuyah et al., 2012).In order to measure accurate density there are two possible options so far. One is that to estimate the density by measured trimmed branch and replaced or use as the density of tree(FAO, 2012). The second option is that by using density table which means estimation of density using literature based density (Aboal et al., 2005). However, this study used trimmed branch density as whole tree density. Wood specific density is an important predictive variable in of developed models. Its importance may notbe obvious if one is interested in estimating the biomass in an old-growth forest dominated by hardwood species, spanning a narrow range of wood densities. However,Baker et al. (2004) have shown that ignoring variations in wood density should result in poor overall prediction of the stand AGB. Direct wood density measurements are seldom available for the trees in permanent forest stands. Many scientists recommended to use a species-level average(Brown et al., 1989, Nelson et al., 1999, Chave et al., 2001), or, if detailed floristic information is unavailable, a stand-level average (Baker et al., 2004). Compilations of species-specific wood specific density are being made available to facilitate this procedure.

\section{General Equation Vs Species Specific Equation}

Various authors have stated that the most important advantage of two-dimensional analytical techniques for estimating above ground biomass of trees is that the same equation is often valid for all tree species within the ecosystem under consideration(Whittaker and Woodwell, 1968). This has been confirmed for forest types including tropical forest and temperate deciduous woodland as mentioned in (Duvigneaud, 1974). Many generalized equations that are applicable for biomass estimation depend on the ecological zones of the forest. For forests like WofWasha (dry afromontane forest) the equation of $Y=34.4703$ - 8.0671 DBH + 0.6589 $\mathrm{DBH}^{2}$ (Brown, 1997) had been used as a generalized equation. According to this equation the mean biomass of Juniperus procera and Podocarpus falcatus became $2,133.99 \mathrm{~kg}$ and $2,058.77 \mathrm{~kg}$ respectively for 24 individuals. However, the values were $1,600.28 \mathrm{~kg}$ and $1,406.55 \mathrm{~kg}$ for Juniperus procera and Podocarpus falcatus respectively for species specific measurement procedure that is shown in Table 6. When the results are compared, these collected through non- distractive, species specific estimation of biomass with generalized equations they had significance difference at the total amount of biomass for both Juniperus procera and Podocarpus falcatus species as shown in Figure 6. However, species specific models or equations are more accurate for estimation of biomass (Litton and Boone Kauffman, 2008), and there is no universally accepted allometric equation as such (Wang, 2006).

Table 6. Comparison between generalized equation and species specific and equation measured biomass of Juniperus procera and Podocarpus falcatus.

\begin{tabular}{ll}
\hline Biomass & Mean in kg \\
\hline Total biomass of Juniperus & 1600.28 \\
General equation total biomass of Juniperus & 2133.99 \\
Total biomass of Podocarpus & 1406.55 \\
General equation total biomass of Podocarpus & 2058.77 \\
\hline
\end{tabular}




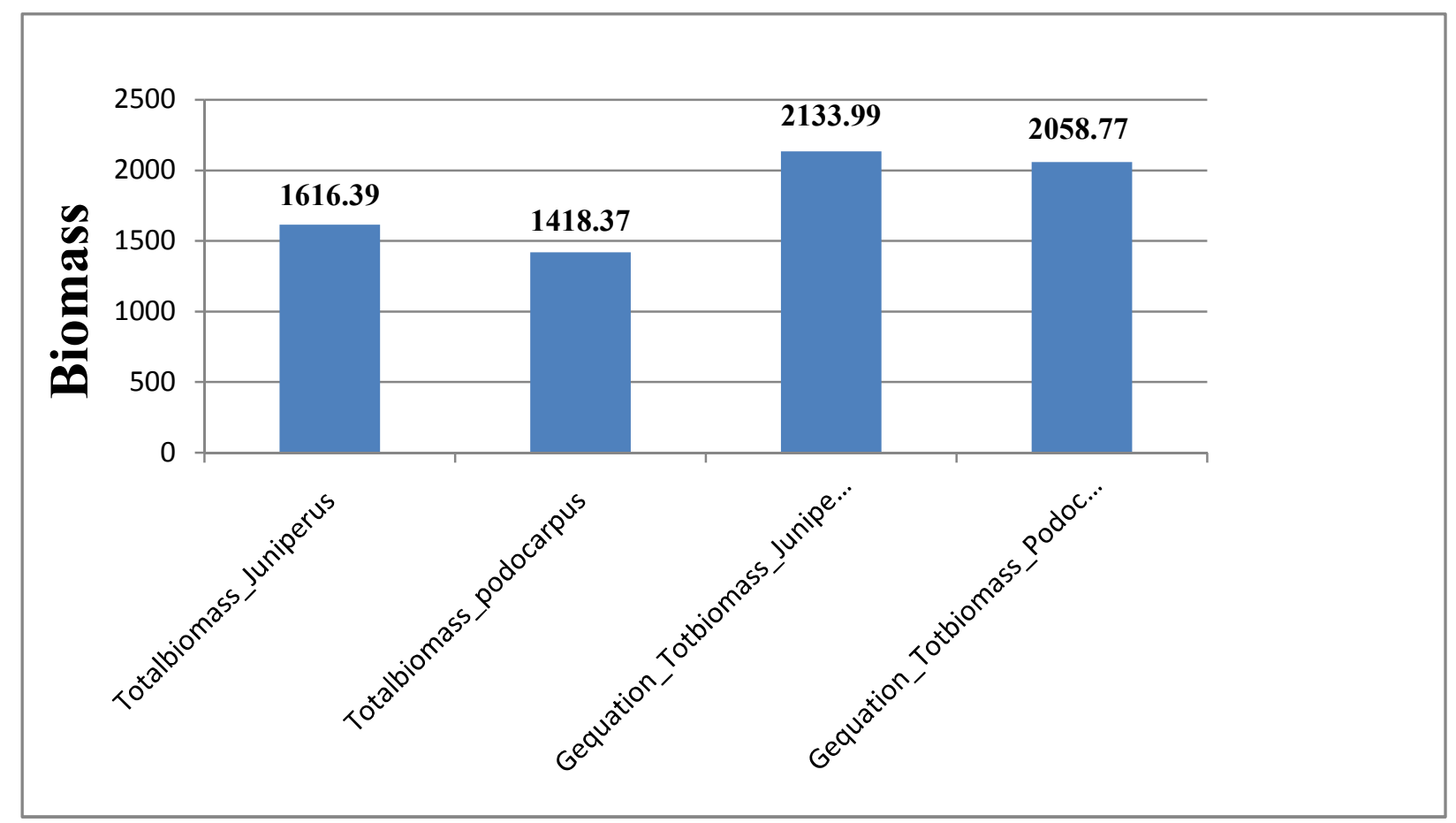

Figure 6. Comparison of biomass through generalized equation and species specific way of estimation.

The results of the present study suggest that the assumption that the same equation is often valid for all tree species within the ecosystem under consideration is not valid in Wof-Washa forest, because there were significant differences between the allometric equations for all the species pairs. On the other hand, we did not detect significant among-forest-type within-species differences in allometric equations in the present study, so that the species studied show the same allometric relationships (relating DBH and AGB) independently of the type of forest, thereby allowing all the data for one species to be pooled to derive a single allometric equation for each species.

The linear biomass equation based on $\mathrm{DBH}$ provided a highly significant $(\mathrm{p}>0.000)$ fit for Juniperus procera and Podocarpus falcatus tree species of all tree biomass compartments as shown in Figures 4 \&5. The form of allometric equation varies widely differing from one another in terms of model selection but the most commonly used is linear regression equation, i.e., $\mathrm{Y}=\mathrm{a}+\mathrm{bX}$, where $\mathrm{Y}$ is the biomass and $\mathrm{X}$ is the DBH (Ketterings et al., 2001, Kuyah et al., 2012, Dudley and Fownes, 1992). Using this model, many authors develop allometric equation for specific species. According to (Aboal et al., 2005), they try to estimate the total above ground dry biomass, generally considered standard regression models in which the predictor was $\mathrm{DBH}$, and models in which both $\mathrm{DBH}$ and height were used as predictors. In both cases AGB was subjected to a natural $\log$ transformation to normalize its distribution. For all tree species the model selected was a double logarithmic model, using $\mathrm{DBH}$ as predictor (i.e., models of the type $\ln \mathrm{AGB}=\mathrm{a}+\mathrm{b} \ln \mathrm{DBH}$ ) other models (e.g. polynomial models) gave a worse fit, and were rejected. Likewise, this study developed allometric equation for all compartment of trees for the two species, Juniperus procera and Podocarpus falcatus, and a double logarithmic model had best fit. For Juniperus procera, the $\mathrm{r}^{2}$ value of linear model was 0.69 , for trimmed and for dry section, AGB and Total biomass were 0.83 . However, for double logarithmic model, the $r^{2}$ value was similar for trimmed with linear model but for dry section, AGB and Total biomass hadr $^{2}$ value of 0.86 for all untrimmed components. For Podocarpus falcatus, the $\mathrm{r}^{2}$ value of linear model was 0.76 , for trimmed and for dry section, AGB and Total biomass was 0.79. However for double logarithmic model, the $\mathrm{r}^{2}$ value was 0.78 for trimmed and for dry section, AGB and Total biomass had $\mathrm{r}^{2}$ value of 0.84 for all untrimmed components as mentioned in result section earlier.

\section{Conclusion and Recommendations}

\subsection{Conclusion}

Uncertainty in biomass and carbon stocks largely results due to lack of species specific allometric equations for different species. Limited number of studies have been attempted to develop such equations. This allometric equation can be reliably used by the researchers and forest managers to calculate above and belowground biomass of Juniperus procera and Podocarpus falcatus in Ethiopia within the dry forests and elsewhere. In this study it is proposed that the following equation were developed as appropriate equation from 30 to $100 \mathrm{~cm}$ diameter class for 24 
Juniperus procera and Podocarpus falcatus species in WofWasha Forest. The linear model that is developed for prediction of total biomass explained (83\% and 79\%) variation in biomass for Juniperus procera and Podocarpus falcatus respectively.

The generalized equations developed from the present study for Juniperus procera taking in to consideration each compartment of the tree were:

- Trimmed $=0.095+0.029(\mathrm{DBH}), \quad \ln ($ Trimmed $)=\ln (-$ $2.472)+0.657$ (basal diameter).

- $\ln ($ Dry section $)=\ln (-2.58)+2.34 \ln (\mathrm{DBH})$.

- $\ln (\mathrm{AGB})=\ln (-2.48)+2.321 \ln (\mathrm{DBH})$.

- $\ln ($ Total biomass $)=\ln (-2.3072)+2.321 \ln (\mathrm{DBH})$.

Similarly species specific equations have been developed for Podocarpus falcatus for each compartment of the trees.

- Trimmed $=0.025+0.035$ (basal diameter $)$, $\ln ($ Trimmed $)=\ln (-2.972)+0.863 \ln (\mathrm{DBH})$.

- $\ln ($ Dry section $)=\ln (0.361)+1.79 \ln (\mathrm{DBH})$.

- $\ln (\mathrm{AGB})=\ln (-0.307)+1.7855 \ln (\mathrm{DBH})$.

- $\ln ($ Total biomass $)=\ln (-0.125)+1.785 \ln (\mathrm{DBH})$.

The total biomasses of Juniperus procera and Podocarpus falcatus which are indigenous plants have an average value of $1,600.281 \mathrm{~kg}$ and $1,406.55 \mathrm{~kg}$ respectively. The most dominant component of Juniperus procera and Podocarpus falcatus are the trunk and large branches (Dry section) which have $82.7 \%$ of the total biomass for both species. Generalized biomass allometric equations that ignore tree species provide reasonable estimation of biomass for Juniperus procera and Podocarpus falcatus species but the species effect was statistically significant. This emphasized that the importance of species specific allometric equations for more precise estimation of biomass. This study indicated Forest has potential in the mitigation of global warming and adaptation to climate change and hence by considering CDM market price US\$ 4-12 Mg ha-1yr-1. Market values have virtually collapsed during the 2 years after the 2008 worldwide bank crash and inclined to cautiously use a market value of $\$ 4 / \mathrm{tCO}_{2} \mathrm{e}$. Hence $1600.281 \mathrm{~kg}$ and $1406.55 \mathrm{~kg}$ of Juniperusprocera and Podocarpusfalcatus respectively had $2,936.51 \mathrm{~kg}$ and $2581.10 \mathrm{~kg} \mathrm{CO}_{2}$ respectively. Then, Juniperus procera might had 11.8 US\$ and Podocarpus falcatus also had10.3US\$ for single individual. This money could contribute to improve the rural livelihoods, protecting good forest governance, reducing biodiversity loss and increases adaptation strategy to the changing climate scenario.

\subsection{Recommendations}

Effective utilization of the Forest on sustainable basis requires effective management. Many international agreements agreed on that accounting of carbon is the main and relatively easy way to combat climate change. Development of allometric equation is the method that all carbon auditing estimation procedure follows. In order to develop allometric equation for accurate estimation of biomass the following listed pointes should be put into consideration;

- Formulating allometric equation through species specific method for all the indigenous tree species that are found in Wof-Washa Forest.

- Encompass all the possible diameter class of tree species.

- Even though non-destructive method of biomass estimation is environmentally friendly, it is better to harvest a few trees to compare the biomass result obtained from direct measurement and indirect (nondestructive) measurement.

- Measurement of density is preferable to estimate directly or destructively in order to get accurate estimation.

\section{References}

[1] ABOAL, J. R., ARÉVALO, J. R. \& FERNÁNDEZ, Á. 2005. Allometric relationships of different tree species and stand above ground biomass in the Gomera laurel forest (Canary Islands). Flora - Morphology, Distribution, Functional Ecology of Plants, 200, 264-274.

[2] BAKER, T. R., PHILLIPS, O. L., MALHI, Y., ALMEIDA, S., ARROYO, L., DI FIORE, A., ERWIN, T., KILLEEN, T. J., LAURANCE, S. G. \& LAURANCE, W. F. 2004. Variation in wood density determines spatial patterns inAmazonian forest biomass. Global Change Biology, 10, 545-562.

[3] BASUKI, T., VAN LAAKE, P., SKIDMORE, A. \& HUSSIN, Y. 2009. Allometric equations for estimating the above-ground biomass in tropical lowland Dipterocarp forests. Forest Ecology and Management, 257, 1684-1694.

[4] BEKELE, T. 1993. Vegetation ecology of remnant Afromontane forests on the Central Plateau of Shewa, Ethiopia.

[5] BROWN, S. 1997. Estimating biomass and biomass change of tropical forests: a primer, Food \& Agriculture Org.

[6] BROWN, S., GILlespie, A. J. \& LUGO, A. E. 1989. Biomass estimation methods for tropical forests with applications to forest inventory data. Forest science, 35, 881902.

[7] CHAVE, J., RIÉRA, B. \& DUBOIS, M.-A. 2001. Estimation of biomass in a neotropical forest of French Guiana: spatial and temporal variability. Journal of Tropical Ecology, 17, 7996.

[8] DUDLEY, N. \& FOWNES, J. 1992. Preliminary biomass equations for eight species of fast-growing tropical trees. Journal of tropical forest science, 5, 68-73.

[9] DUVIGNEAUD, P. 1974. A synthesis of ecology: populations, communities, ecosystems, biosphere and noosphere, Doin, editeurs.

[10] FAO 2012. Manual for building tree volume and biomass allometric equations: from field measurement to prediction.

[11] GEIDER, R. J., DELUCIA, E. H., FALKOWSKI, P. G., FINZI, A. C., GRIME, J. P., GRACE, J., KANA, T. M., LA ROCHE, J., LONG, S. P. \& OSBORNE, B. A. 2001. Primary productivity of planet earth: biological determinants and physical constraints in terrestrial and aquatic habitats. Global Change Biology, 7, 849-882. 
[12] IPCC 2007. Climate change 2007-the physical science basis: Working group I contribution to the fourth assessment report of the IPCC, Cambridge University Press.

[13] KETTERINGS, Q. M., COE, R., VAN NOORDWIJK, M. \& PALM, C. A. 2001. Reducing uncertainty in the use of allometric biomass equations for predicting above-ground tree biomass in mixed secondary forests. Forest Ecology and management, 146, 199-209.

[14] KUYAH, S., DIETZ, J., MUTHURI, C., JAMNADASS, R., MWANGI, P., COE, R. \& NEUFELDT, H. 2012. Allometric equations for estimating biomass in agricultural landscapes: I. Aboveground biomass. Agriculture, Ecosystems \& Environment, 158, 216-224.

[15] LITTON, C. M. \& BOONE KAUFFMAN, J. 2008. Allometric models for predicting aboveground biomass in two widespread woody plants in Hawaii. Biotropica, 40, 313-320.

[16] MACDICKEN, K. G. 1997. A guide to monitoring carbon storage in forestry and agroforestry projects, Winrock International Institute for Agricultural Development USA.

[17] NELSON, B. W., MESQUitA, R., PEREIRA, J. L., DE SOUZA, S. G. A., BATISTA, G. T. \& COUTO, L. B. 1999. Allometric regressions for improved estimate of secondary forest biomass in the central Amazon. Forest ecology and management, 117, 149-167.

[18] PEARSON, T., WALKER, S. \& BROWN, S. 2013. Sourcebook for land use, land-use change and forestry projects.

[19] SINGH, V., TEWARI, A., KUSHWAHA, S. P. \& DADHWAL, V. K. 2011. Formulating allometric equations for estimating biomass and carbon stock in small diameter trees. Forest Ecology and Management, 261, 1945-1949.

[20] TEKETAY, D. \& BEKELE, T. 1995. Floristic composition of Wof - Washa natural forest, Central Ethiopia: Implications for the conservation of biodiversity. Feddes Repertorium, 106, 127-147.

[21] UNFCCC. United Nations Framework Convention on Climate Change: Handbook. United Nations Framework Convention on Climate Change: handbook, 2006. UNFCCC.

[22] WANG, C. 2006. Biomass allometric equations for 10 cooccurring tree species in Chinese temperate forests. Forest Ecology and Management, 222, 9-16.

[23] WHITTAKER, R. H. \& WOODWELL, G. M. 1968. Dimension and production relations of trees and shrubs in the Brookhaven Forest, New York. The Journal of Ecology, 1-25. 